\title{
LOCAL-REGIONAL POLLUTION CONTROL PROGRAMS:
}

A DOUBLE VIOLATION OF OPTIMALITY

by

Frank J. Alessio*

Traditional economic theory argues, on the basis of welfare maximizing models, that a national system of local-regional pollution control programs are destined to supply an amount of pollution abatement which is less than optimal. The essence of the traditional argument is that local-regional pollution control programs fail to account for the external effects; i.e., the externalities are not fully internalized. 1 Although the conclusion about optimality is theoretically correct, the traditional argument is not appropriate for the case of local-regional pollution control programs.

In the case of local-regional pollution control programs, the traditional argument is inappropriate because a non-optimal solution occurs even though localities do internalize the externalities. Each locality recognizes that pollution control in other localities produces external economies for its own abatement program by reducing the amount of pollution that flows into the locality from outside sources. If each locality attempts to internalize these externalities, and thereby reduce the total cost of its own clean-up efforts, the result is an abatement-supply reaction process which produces a level of abatement that is neither globally optimal, ${ }^{2}$ as traditional economic theory suggests, nor locally optimal. It is the attempt to internalize the externalities that forces local pollution. control programs into a double violation of optimality.

Consider a universe consisting of two adjacent but politically independent localities, locality $i$ and locality $j$. Each locality, in the process of producing and consuming a bill of goods, pollutes its own environment. A portion of each locality's pollution spills-over as an external diseconomy into the other locality. Each locality pursues an independent abatement program. To the extent that abatement in each locality is successful, the amount of pollution spill-over is reduced and the external diseconomy forces onto the other locality is lessened. If each locality adjusts to the abatement spill-in by reducing its own level of control operations, the local pollution control programs will supply an amount of abatement which is less than globally optimal, and less than locally optimal. This paper demonstrates that locally operated pollution control programs will be less than optimal--1ocally as well as globally--as a result of the reaction to the abatement spill-in effects alone, traditional economic theory notwithstanding.

\section{Local Control Programs}

For each locality to provide the economically optimal amount of pollution abatement it must equate the marginal benefits of a cleaner environment to the marginal costs of abatement. Define the total benefits of a unit of pollution abatement as the pecuniary plus psychic value of a less polluted environment. That is:

$$
\begin{aligned}
& B=u(A) \\
& u^{\prime}>0, u^{\prime \prime}<0
\end{aligned}
$$

where $B$ is the total benefit derived from the abatement programs, $A$ is the amount of pollution abatement supplied, and $u(A)$ is the pecuniary plus psychic gain from abatement.

*Assistant Professor of Economics at The University of Arizona, Tucson, Arizona. I am indebted to Clark A. Hawkins for many stimulating comments. Summer Research support from the College of Business and Public Administration at the University of Arizona is gratefully acknowledged. 
Define the total costs of a unit of pollution abatement as the pecuniary plus opportunity cost of abatement. Assume, for simplicity, that the pecuniary costs are proportional to the amount of abatement supplied; while the opportunity costs (defined as the value of the foregone consumption of the usual bill of goods due to a diversion of resources to abatement) are an increasing function of the amount of abatement supplied. 3 That is:

$$
\begin{aligned}
& \mathrm{C}=\mathrm{c}(\mathrm{A})+\mathrm{g}(\mathrm{A}) \\
& \mathrm{c}^{\prime}>0, \mathrm{c}^{\prime \prime}=0, \\
& \mathrm{~g}^{\prime}>0, \mathrm{~g}^{\prime \prime}>0,
\end{aligned}
$$

where $C$ is the total cost of abatement, $C(A)$ and $g(A)$ are the pecuniary and opportunity costs of abatement respectively.

Assume that each locality places a psychic value on abatement, and assume that the pecuniary and opportunity costs of abatement in each locality are identical. Then (1) and (2) could be written for each locality as:

$$
\begin{aligned}
& u_{i}\left(A_{i}\right)=G_{i} A_{i}, g_{i}\left(A_{i}\right)=A_{i}^{2} / d, c_{i}\left(A_{i}\right)=c A_{i} \\
& u_{j}\left(A_{j}\right)=G_{j} A_{j}, g_{j}\left(A_{j}\right)=A_{j}^{2} / d, c_{j}\left(A_{j}\right)=c A_{j}
\end{aligned}
$$

where $G_{j}$ and $G_{j}$ represent the pecuniary plus psychic gains from abatement in localities $^{j} i$ and $j$ respectively. Thus, the total satisfaction derived from abatement in each locality is:

$$
\begin{aligned}
S_{i}= & B_{i}-C_{i} \\
& =G_{i} A_{i}-A_{i}^{2} / d-c A, \\
S_{j}= & B_{j}-C_{j} \\
& =G_{j} A_{j}-A_{j}^{2} / d-c A_{j} .
\end{aligned}
$$

Maximizing $\mathrm{S}_{i}$ and $\mathrm{S}_{j}$ with respect to $\mathrm{A}_{i}$ and $\mathrm{A}_{j}$ determines the locally optimal amount of ${ }^{1}$ abatement. That is:

$$
\begin{aligned}
& A_{i}=\left(G_{i}-c\right) d / 2 \\
& A_{j}=\left(G_{j}-c\right) d / 2
\end{aligned}
$$

At this point the abatement authority in each locality observes that the control program in the other locality reduces the amount of pollution in its own locality, because of the spill-over effect. Assume that a constant proportion of the abatement in each locality spill-over into the other. Accordingly, the amount of abatement effective in each locality is:

$$
\begin{aligned}
& \bar{A}_{i}=A_{i}+b A_{j} \\
& \bar{A}_{j}=A_{j}+a A_{i}, \\
& 0<a, b<1
\end{aligned}
$$

where $\mathrm{a}$ and $\mathrm{b}$ represent constant spill-over coefficients.

At the effective levels of abatement, each locality gains some pollution abatement at no pecuniary or opportunity cost. Consequently, each locality realizes that it can enjoy the optimal amount of abatement, given by (4), at a lower total cost to its own citizenry, by reducing its own abatement output and utilizing the spill-over from the other locality. Each locality reduces its own abatement program by an amount equal to the spillover, $b_{i}$ and $a_{i}$ for localities $i$ and $j$ respectively. Therefore, anticipating no reduction by the other locality, the amount of abatement supplied 
by each locality independently adjusts to:

$$
\begin{aligned}
& A_{i}(t+1)=\left(G_{i}-c\right) d / 2-b A_{j}(t) \\
& A_{j}(t+1)=\left(G_{j}-c\right) d / 2-a A_{i}(t),
\end{aligned}
$$

indicating a one-period lag in the adjustment process.

Since both localities adjust, the realized level of abatement in each falls below the locally optimal level, causing each locality to expand its own supply of abatement. This abatement reaction process (i.e., the alternating expansion and contraction of the amount of locally supplied abatement) causes the amount of abatement supplied by each locality to be:

$$
\begin{aligned}
& A_{i}(t+1)=\left[\frac{\left(G_{i}-c\right) d-b d\left(G_{j}-c\right)}{2}\right]+a b A_{i}(t-1) . \\
& A_{j}(t+1)=\left[\frac{\left(G_{j}-c\right) d-a d\left(G_{i}-c\right)}{2}\right]+a b A_{j}(t-1) .
\end{aligned}
$$

Equations (7) are non-homogeneous, second-order, difference equations with constant coefficients. The solution for each equation is: ${ }^{4}$

$$
\begin{aligned}
& A_{i}(t)=K_{1}(a b)^{t / 2}+K_{2}(-a b)^{t / 2}+\left[\frac{\left[\left(G_{i}-c\right)-b\left(G_{j}-c\right)\right] d}{2(1-a b)}\right] \\
& A_{j}(t)=K_{3}(a b)^{t / 2}+k_{4}(-a b)^{t / 2}+\left[\frac{\left[\left(G_{j}-c\right)-a\left(G_{i}-c\right)\right] d}{2(1-a b)}\right]
\end{aligned}
$$

where $\mathrm{K}_{1} \cdot \mathrm{K}_{4}$ are constants whose values are dependent upon the initial values of $A_{i}$ and $A_{j}$.

Since ${ }^{1} 0<a b^{j}<1$, the unique values of $A_{i}$ and $A_{j}$ which result from the reaction process are:

$$
\begin{aligned}
& \lim _{t \rightarrow \infty} A_{i}(t)=A_{i}^{*}=\frac{\left[\left(G_{i}-c\right)-b\left(G_{j}-c\right)\right] d}{2(1-a b)} \\
& \lim _{t \rightarrow \infty} A_{j}(t)=A_{j}^{*}=\frac{\left[\left(G_{j}-c\right)-a\left(G_{i}-c\right)\right] d}{2(1-a b)}
\end{aligned}
$$

$A_{i}^{*}$ and $A_{i}^{*}$ are the final amounts of abatement supplied by localities $i$ and $j$ rêspectively.

Comparing (9) and (1),

$$
\begin{aligned}
& A_{i}^{*}<A_{i} \\
& <\left(G_{i}-c\right) d / 2 \\
& A_{j}^{*}<A_{j} \\
& <\left(G_{j}-c\right) d / 2,
\end{aligned}
$$

indicates that each local pollution control program is operated at a less 
than locally optimal leve1. ${ }^{5}$ Therefore, the attempt to internalize the external economies resulting from pollution control programs in other localities forces each locality into an abatement-reaction process like that summarized in (6) and (7). The result is that the amount of abatement supplied by each locality tends to be less than the optimal amount for that locality.

\section{Global Control Program}

Instead of independent local control programs, assume that a global program is formed to maximize global satisfaction. Total global benefits equal the sum of total benefits from abatement in each locality. That is:

$$
B=G_{i} A_{i}+G_{i} b_{j}+G_{j} A_{j}+G_{j} a_{i}-A_{i}^{2} / d-A_{j}^{2} / d,
$$

where B now represents total global benefits. Similarly, total global costs from abatement production in each locality. That is:

$$
C=\mathrm{CA}_{i}+\mathrm{cA}_{j}
$$

where $\mathrm{C}$ now represents total global costs. Therefore, total global satisfaction becomes:

$$
S=\left(G_{i}+G_{j} a\right) A_{i}+\left(G_{j}+G_{i} b\right) A_{j}-\left(A_{i}^{2}+A_{j}^{2}\right) / d-c\left(A_{i}+A_{j}\right) .
$$

Maximizing $S$ with respect to $A_{i}$ and $A_{j}$, yields the share of the globally optimal amount of abatement to be supplied by each locality. That is:

$$
\begin{aligned}
& A_{i}=\left(G_{i}+G_{j} a-c\right) d / 2 \\
& A_{j}=\left(G_{j}+G_{i} b-c\right) d / 2
\end{aligned}
$$

Therefore, the level of global abatement is:

$$
\begin{aligned}
A & =A_{i}+A_{j} \\
& =\left[\left(G_{i}-c\right)+\left(G_{j}-c\right)+G_{i} b+G_{j} a\right] d / 2 .
\end{aligned}
$$

Comparing (15) with the sum of (4) indicates that the amount of abatement is greater under the global control program than under the local control programs. That is:

$$
\left[\left(G_{i}-c\right)+\left(G_{j}-c\right)+G_{i} b+G_{j} a\right] d / 2>\left[\left(G_{i}-c\right)+\left(G_{j}-c\right)\right] d / 2
$$

implying that the abatement supplied to the entire citizenry of the tworegion area is greater under the global control program.

III. Conclusions

It is the attempt on the part of each locality to internalize the external economies, contrary to the traditional argument, which results in pollution control programs that are less than optimal. The attempt to capture the externalities produces an abatement-reaction process which forces local-regional pollution control programs into a double violation of optimality: They are not optimal at the global level, and neither are they optimal at the local level. 


\section{FOOTNOTES}

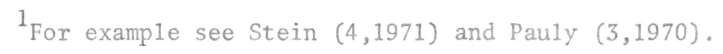

${ }^{2}$ Global Optimality is defined as optimality for the United States as a whole.

${ }^{3}$ Under the assumption that pollution control programs become increasingly capital intensive as the amount of abatement supplied increases, the amount of capital inputs diverted away from the production of the usual consumption goods increases at an increasing rate. The result is that, in the absence of technical innovation, production of the usual consumption goods increases at a decreasing rate. Therefore, the utility loss associated with the lost consumption of the usual goods increases at an increasing rate, and so does the opportunity cost. On this point, see Alessio, $(1,1971)$ pp. 84-92.

${ }^{4}$ Goldberg $(2,1958)$ pp. 135-147. yields:

${ }^{5}$ It is easily demonstrated that $A_{i}^{*}<A_{j}^{*}$. Substituting (9) into (5)

$$
\bar{A}_{i}=\frac{\left[\left(G_{i}-c\right)-b\left(G_{j}-c\right)\right] d+b\left[\left(G_{j}-c\right)-a\left(G_{i}-c\right)\right] d}{2(1-a b)}
$$

which reduces to $\bar{A}_{i}=\left(G_{i}-c\right) d / 2=A_{i}$. It is $c l e a r_{*}$ that $A_{i}^{*}<\bar{A}_{i}$. There fore, $A_{i}^{*}<A_{i}$. A simila demonstration exists for $A_{j}^{*}$.

\section{REFERENCES}

1. Allessio, Frank J., "The Opportunity Cost of Pollution Abatement in a Steady-State Expanding Economy," The Annals of Regional Science; vol. no. 1, pp. 84-92.

2. Goldberg, Samue1, Introduction to Difference Equations, (John Wiley and Sons, Inc.: New York, 1961) pp. 135-147.

3. Pauly, Mark V., "Optimality, Public Goods, and Local Governments: A General Theoretical Analysis," Journal of Political Economy; vol. 78, no. 3, pp. 572-585.

4. Stein, Jerome L.,"The 1971 Report of the President's Council of Economic Advisers: Micro-Economic Aspects of Public Policy," American Economic Review; vol. LXI, no. 4, pp. 531-537. 